NASA Technical Memorandum 104437

AIAA-91-1902

\title{
Static Performance Tests of a Flight-Type STOVL Ejector
}

Wendy S. Barankiewicz

Lewis Research Center

Cleveland, Ohio

Prepared for the

27th Joint Propulsion Conference

cosponsored by AIAA, SAE, ASME, and ASEE

Sacramento, California, June 24-27, 1991 


\title{
STATIC PERFORMANCE TESTS OF A FLIGHT-TYPE STOVL EJECTOR
}

\author{
Wendy S. Barankiewicz \\ National Aeronautics and Space Administration \\ Lewis Research Center \\ Cleveland, Ohio 44135
}

\begin{abstract}
$\underline{\text { Abstract }}$
The design and development of thrust augmenting STOVL ejectors has typically been based on experimental iteration (i.e. trial \& error). In this investigation, static performance tests of a full-scale vertical lift ejector were performed at primary flow temperatures up to $1560^{\circ} \mathrm{R}$ $\left(1100^{\circ} \mathrm{F}\right)$. Flow visualization (smoke generators and yarn tufts) were used to view the inlet air flow, especially around the primary nozzle and end plates. Performance calculations are presented for ambient temperatures close to $480^{\circ} \mathrm{R}\left(20^{\circ} \mathrm{F}\right)$ and $535^{\circ} \mathrm{R}\left(75^{\circ} \mathrm{F}\right)$ which simulate "seasonal" aircraft operating conditions. Resulting thrust augmentation ratios are presented as functions of nozzle pressure ratio and temperature.
\end{abstract}

\section{$\underline{\text { Introduction }}$}

Short take-off and vertical landing (STOVL) aircraft are potential candidates for future high performance aircraft. Successful STOVL designs depend heavily on the propulsion system development, whereby, both vertical lift and forward thrust must be attained without drastically increasing the aircraft's weight or cross sectional area.

One method of achieving STOVL capability in an aircraft is through the use of thrust augmenting ejectors. Basically, an ejector is a pumping device through which large amounts of air are drawn from the atmosphere by the entrainment action of the primary jet shear layer. As shown in Figure 1, engine air is ducted through a row of nozzles between the wing and fuselage of the aircraft. Thrust augmentation results when the entrained secondary air mixes with the primary flow, increasing total mass flow and thus the vertical thrust.

The original ejector concept [5] supplied fan flow to the ejector primary nozzles using a separate flow engine. Although properly designed ejectors perform best with cool primary air, a mixed flow system would eliminate the bypass ratio dependence and result in a simplified system. As a consequence, the gas temperature available for the ejector primary nozzles is now elevated from fan duct levels to mixed flow levels. As part of the STOVL component research, the NASA Lewis Research Center in conjunction with Boeing Military Airplanes and Boeing de Havilland - has conducted a series of tests on a full-scale lift ejector configuration with hot primary flow.

This unique, ejector testing was performed at the NASA Lewis Research Center's Powered Lift Facility (PLF) from June, 1990 thru January, 1991; and signifies the first design point (both pressure and temperature) testing of a full-scale thrust augmenting ejector. The design point of this ejector was at a primary-nozzle pressure ratio of 2.7 and a primary-air temperature of $1560^{\circ} \mathrm{R}$. By providing such a database, ejector design technology can be verified and computer codes calibrated to evaluate ejector performance in future STOVL aircraft.

The major objectives of this test were to measure thrust augmentation levels for both "cold" and "hot" primary flows in order to validate the ejector design and determine the effects of primary jet temperature on thrust augmentation. To accomplish these objectives, two series of tests were conducted:

(1) "cold" flow primary, where the supply air was not heated.

(2) "hot" flow primary, where the supply air was heated over a range of temperatures up to a maximum temperature of $1560^{\circ} \mathrm{R}$.

In the cold flow tests, several modifications were made to enhance the shear layer mixing and improve the ejector performance. Hot flow testing was then performed with a similar configuration; only slight changes were made to allow for thermal expansion of the ejector duct.

Test results are presented through plots of thrust augmentation vs. nozzle pressure ratio and ejector primary temperature. Plots of exit rake thrust augmentation vs. rake location are also compared.

\section{$\underline{\text { Test Facility }}$}

The Powered Lift Facility is an outdoor facility comprised primarily of a sea-level thrust balance and dry air supply. The thrust balance itself is a triangular- 
shaped, multi-directional force measuring system fifteen feet above the ground, with load cells arranged to measure thrust levels in the lateral, vertical, and axial directions as well as moments about all three axes (roll, pitch, and yaw). The ejector was installed on the PLF thrust stand as shown in Figure 2. For test purposes the ejector was turned on its side, measuring thrust in the axial direction (parallel to the ground plane). Air flow to the ejector primary nozzles was measured in the air supply pipe using an ASME flow nozzle. Similarly, a turbine meter measured fuel flow in the fuel supply line.

\section{Model and Instrumentation}

The ejector model is an array of ten notched-cone nozzles (primary flow) placed along the throat of a converging/diverging nozzle shroud. For this model, the diffuser exit to throat area ratio is 1.89 , and although it is similar to the E-7 ejector tested at the PLF in 1987 [5], the present model has a larger secondary to primary area ratio $A_{s} / A_{p}$ of 30 compared with 23 , a shorter mixing length, and a more realistic flight-type inlet (see Figure 2 for a view of the inlet, and Figure 3 for the ejector exit plane). This particular model was designed for a primary nozzle temperature of $1560^{\circ} \mathrm{R}$ and pressure ratio of 2.7 .

Also included in the research system is the onbalance piping and modified $\mathrm{J}-58$ burner needed to heat the supply air. Several pressure and temperature measurements were taken to set inlet conditions and monitor burner pressure drops. Figure 4 outlines the duct instrumentation and components of the ejector onbalance piping system. Two perforated plates acting as flow straighteners are shown at either end of the burner. The first straightens the flow from the elbow, while the second is present to help alleviate temperature distortion at the burner exit. An expandable section (bellows) is also included to allow for thermal expansion of the duct.

The model itself contains approximately 130 pressure and 45 temperature measurements falling into four groups:

(1) Ejector-Surface Static-Pressure Taps

(2) Ejector-Surface Thermocouples

(3) Ejector-Exit Rake Instrumentation

(4) Primary-Nozzle Static-Pressure Taps

To provide information on loading and pressure distribution, static taps are located on the ejector wall between primary nozzles \#5 and \#6 (Figure 5.a), and on the upstream end-plate (Figure 5.b). Four more taps are located on the downstream end-plate. Ejector-throat statics (Figure 5.c) are also present to confirm chordwise uniformity of the throat Mach number. For structural design purposes, thermocouples (Figure 5.d) are located along both the ejector wall (one row between nozzles \#3 and \#4 and one row in line with nozzle \#4) and along the center line of the upstream end-plate. All thermocouples are heavily insulated to prevent heat loss on the outside surface. As shown in Figure 3, a rake containing twenty total pressure tubes, nine static pressure tubes, and ten thermocouples is placed spanwise across the ejector exit. To obtain measurements in the diffuser exit plane, the rake is incrementally moved through the 96 inch chord length (left to right in Figure 3). Also, each nozzle has an internal reference static pressure tap previously calibrated against average nozzle exit total pressure for calculation of isentropic primary thrust.

\section{Testing Procedure}

Steady-state performance testing consisted of pressure, temperature, and thrust measurements over a nozzle pressure ratio (NPR) range of 1.6 to 3.0. These pressure runs were conducted with primary flow temperatures of $1560^{\circ} \mathrm{R}, 1360^{\circ} \mathrm{R}, 1160^{\circ} \mathrm{R}$, and a cold flow of approximately $530^{\circ} \mathrm{R}$ (temperature of facility air supply without the burner ignited). For the hot temperatures, the steady state max-to-min temperature variation was approximately $\pm 20^{\circ} \mathrm{R}$ based on the burner system capability. The cold flow primary temperature did not vary as much during each test run; however, since the PLF is an outside facility, primary and secondary air temperatures are lower for the tests conducted in the winter months than in the summertime.

To help analyze the diffuser flow, rake surveys were conducted at NPR $=2.7$ for the different temperatures. Several types of flow visualization techniques were also employed to pinpoint problem flow areas. These included: yarn tufts on the ejector-inlet and nozzle-root areas, paint dots on the diffuser and nozzles, and smoke generation around the model inlet to follow the secondary flow entrainment path.

\section{Discussion of Results}

In this discussion, ejector performance is measured by the thrust augmentation ratio:

$$
\phi=\frac{\text { total thrust }}{\text { primary-nozzle ideal thrust }}=\frac{\text { load cell measurement }}{\text { isentropic thrust }}
$$

where isentropic thrust is computed from the internal nozzle static pressure taps and the supply pipe mass flow rate. During the rake surveys a second thrust parameter is defined as: 


\section{$\phi_{R}=\frac{\text { rake thrust }}{\text { isentropic thrust per inch }}$}

This represents the total rake augmentation per inch at each chordwise rake location. In this case, rake thrust is computed from the rake total-to-static pressure ratio.

\section{Cold Flow Tests}

By comparison with control volume predictions based on previous E-7 test data, the original configuration (Figure 6, inlet door) showed lower augmentation ratios then expected. To investigate possible causes, an analysis of the flow field was conducted using both rake surveys and flow visualization.

As described under the Model and Instrumentation section, the rake surveys generated pressure and temperature data for the entire exit plane. Chordwise analysis of the exit flow (using the average spanwise augmentation) indicated separation off of the upstream inlet radius and poor chordwise mixing; while the spanwise pressure distribution (at each chordwise location) indicated separation on both end-walls, poor spanwise mixing, and a strong attachment of the primary nozzle flow to the diffuser walls.

Several flow visualization techniques were used to asses the inlet flow field condition. Yarn tufts and paint dots placed on the inlet surface and nozzles indicated inlet door separation and recirculation at the nozzle roots. The use of smoke generators confirmed separation off the upstream inlet radius, as the smoke entrainment into the secondary stream bypassed the first nozzle (not enough flow near the wall). This was also shown by the lack of dead bugs brought in by the secondary air on the leading edge of primary-nozzle \#1 (see Figure 7(c) for location of nozzle \#1).

Modifications to the model were then made to reduce inlet loss, and enhance mixing. These configuration changes are summarized below:

(a) Replacing inlet door with a radius (Figure 7(b))

(b) Nozzle root fairings (Figure 7(a))

(c) Plywood spacer located flush with downstream end plate (Figure 7(c))

(d) Primary-nozzle cutback of 0.125 " on all nozzles ( $0.2^{\prime \prime}$ on center nozzles)

(e) Downstream vertical plate (Figure 7(a) \& (b))

(f) Larger upstream end radius (Figure 7(b))

(g) Nozzle leading edge fairings (Figure 7(a))

Performance curves (Figure 6) for configurations (a)-(d) show a gradual, but significant increase in the augmentation ratio. The first configuration change involved replacing the inlet door with a leading edge radius, decreasing the inlet separation such that $\Delta \phi$ was nominally +0.022 . For configuration (b), fairings were installed at the primary nozzle roots to reduce the nozzle "bluff body" separation. Figure 6 shows that this modification has a greater effect at lower NPRs. This could be explained as follows: In theory, a favorable pressure gradient delays separation and results in greater performance. At higher NPR the secondary flow accelerates faster around the primary nozzle, resulting in a more favorable pressure gradient. Therefore, the addition of the fairings have less of an effect at high NPR because they already have a favorable pressure gradient.

Since the ejector is designed for a hot primary temperature of $1560^{\circ} \mathrm{R}$, thermal expansion of the ejector plenum was expected to cause some degradation of performance for the cold flow tests. As shown in Figure $7(\mathrm{c})$, the ejector primary nozzle plenum is attatched to the ejector shroud between the second and third nozzle. Upon heating, plenum expansion to the right of this point is adjusted for in the upstream bellows, while free expansion occurs to the left. At a primary flow temperature of $1560^{\circ} \mathrm{R}$ the nozzles are in their design locations. Any decrease in ejector primary temperature results in a slightly shorter plenum, causing the primary jet flow to shift away from the wall and decrease local thrust augmentation. To alleviate the expansion gap in the cold flow configuration, a plywood spacer [configuration change (c)] was installed. This not only increased augmentation levels on the downstream endplate, but also the overall augmentation $(\Delta \phi=+0.03$ from the root fairings curve). For clarity, this curve does not appear in Figure 6.

Since the primary nozzle flow was attaching to the diffuser walls, the primary-nozzle exit was cut back (configuration (d)). Nozzle corners were cut to redirect the primary flow of the outside plumes away from the diffuser wall and increase flow mixing in the spanwise direction. Augmentation ratio $\phi_{\mathrm{R}}$ as measured by the ejector-exit rake before the nozzles were cut back is shown in Figure 8(a); after cutback in Figure 8(b). By comparing the two one can see an increase in chordwise performance, however the large fluctuations in ejectorrake augmentation indicate low chordwise mixing. Again, a small increase in the overall thrust augmentation was noted at the design point (Figure 6).

Configurations (e)-(g) on the other hand, were not designed to increase the overall ejector performance, only the end-wall augmentation. Effects of these end plate adjustments were examined through the exit rake 
augmentation distributions of Figure 8(c). Comparing the "before and after" plots, all end adjustments do exhibit increased rake augmentation. At the upstream end-plate the larger end radius performed much better than the leading edge fairings (rake augmentation increases $18.8 \%$ vs $7.6 \%$ at nozzle \#1), although no attempt was made to optimize the angle of the fairings. However, even though the vertical plate provides a $6.1 \%$ increase in rake augmentation at the downstream endplate, by decreasing the mixing from nozzles \#6-\#9 it introduces more problems than the separation.

The highest cold flow augmentation ratio was obtained when incorporating changes (a)-(d). This data is shown in Figure 9. The two curves represent the different ambient (secondary flow) temperatures between the January and August runs where:

\begin{tabular}{c|c|c|}
\multicolumn{1}{c}{} & \multicolumn{1}{c}{ January } & \multicolumn{1}{c}{ August } \\
\cline { 2 - 3 } $\mathrm{T}_{\text {ambient }}$ & $480 \mathrm{R}$ & $535 \mathrm{R}$ \\
\cline { 2 - 3 } $\mathrm{T}_{\text {primary }}$ & $510 \mathrm{R}$ & $540 \mathrm{R}$ \\
\cline { 2 - 3 } & &
\end{tabular}

Note that these are the average temperatures for each run. Actual air supply (primary) temperature increased gradually, while ambient temperature decreased slightly throughout each run. Greater scatter in the January data probably results from the larger $\Delta \mathrm{T}_{\text {primary }}\left(15^{\circ} \mathrm{R}\right.$ in January, $5^{\circ} \mathrm{R}$ in August). As $\mathrm{T}_{\text {primary }}-\mathrm{T}_{\text {secondary }}$ increases, the augmentation decreases. As the ambient temperature decreased, augmentation ratio decreased $\sim 2 \%$,

\section{Hot Flow Tests}

Although the configuration chosen for the hot flow tests does not incorporate any of the end effect "fixes", it does correspond with the cold flow configuration that had the highest overall augmentation. Major features of this configuration include:

(a) Replacing inlet door with radius

(b) Nozzle root fairings

(c) No downstream end-plate spacer, high temperature plenum expansion occurs.

(d) Primary-nozzle cut back

Constant temperature performance curves for several different ejector inlet temperatures (Figure 10) show a thrust augmentation loss as the primary nozzle temperature increases. The same decrease in thrust augmentation can be seen while keeping the nozzle pressure ratio constant at 2.7 and varying ejector inlet temperature (Figure 11). Data is presented for both ambient temperature levels as described in the cold flow section, and indicates that the hot flow performance is similarly affected by ambient temperature differences. As the ambient temperature decreased, augmentation ratio decreased approximately $2 \%$. It is interesting to note that decreasing the secondary flow temperature by $30^{\circ} \mathrm{R}$ reduces the augmentation ratio approximately half as much as raising the primary temperature $1000^{\circ} \mathrm{R}$ above ambient $(\Delta \phi \approx-0.04$ vs. $\Delta \phi \approx-0.09)$.

Significant scatter is present in the augmentation curves of Figure 10, probably due to the $\pm 20^{\circ} \mathrm{R}$ inlet temperature deviations (burner adjustment error). This is not seen in Figure 11 where the nozzle pressure ratio is kept constant at 2.7 since NPR, which is indicative of air-supply pressure, can be controlled with more accuracy than primary-flow temperature, which is dependent on maintaining a constant burner fuel flow.

The design point chordwise rake performance (Figure 12) shows better mixing than the cold flow rake performance (Figure 8). The downstream end-wall peak augmentation is now more consistent with center flow; an increase occurring with plenum expansion to a level consistent with the corrected cold flow. However, since this configuration does not reflect the upstream end changes, some lower augmentation in the vicinity of nozzle \#1 can be seen. Still present is the same low spot between nozzles \#6 \& \#7, indicating that the effect is not one of temperature but of nozzle manufacture or installation.

\section{$\underline{\text { Concluding Remarks }}$}

Static tests of a full-scale lift ejector showed that at a primary-nozzle pressure ratio of 2.7 , thrust augmentation ratios of 1.47 (primary-jet temperature at $1560^{\circ} \mathrm{R}$ ) to 1.59 (primary jet temperature at ambient) were obtained. This ejector had a secondary to primary area ratio of 30 , and a diffuser exit to throat area ratio of 1.89.

Cold flow augmentation ratios were increased from 1.52 to 1.59 by several modifications which decreased inlet losses and increased mixing. Both hot and cold data showed approximately a $2 \%$ reduction in the augmentation ratio as the secondary (ambient) temperature decreased roughly $40^{\circ} \mathrm{R}$ (i.e. $\mathrm{T}_{\text {primary }}$ $\mathrm{T}_{\text {secondary }}$ increased). Augmentation reduction seemed to occur faster when the secondary temperature decreased than when the primary temperature increased.

Although the cold flow tests resulted in a higher overall augmentation, the hot flow exit-rake 
augmentation distributions showed a more uniform profile having a smaller peak-to-valley distance; indicative of better mixing. In general, the exit rake distributions showed less mixing than expected, but exit temperatures and pressures remained low.

Rake augmentation ratio was much lower near the fore and aft ends of the ejector than in the middle. If one were to ignore both the deficit between nozzles \#6 and \#7 and the end effect degradation, a closer examination of the rake distribution would yield an integrated rake augmentation in the vicinity of 1.70 . Thus, improvements to ejector efficiency near the end plates is seen as the key to obtaining higher augmentation ratios.

\section{$\underline{\text { References }}$}

1. Batterton, P.G. and Blaha, B.J., "NASA Supersonic STOVL Propulsion Technology Program," NASA TM-100227, 1987.

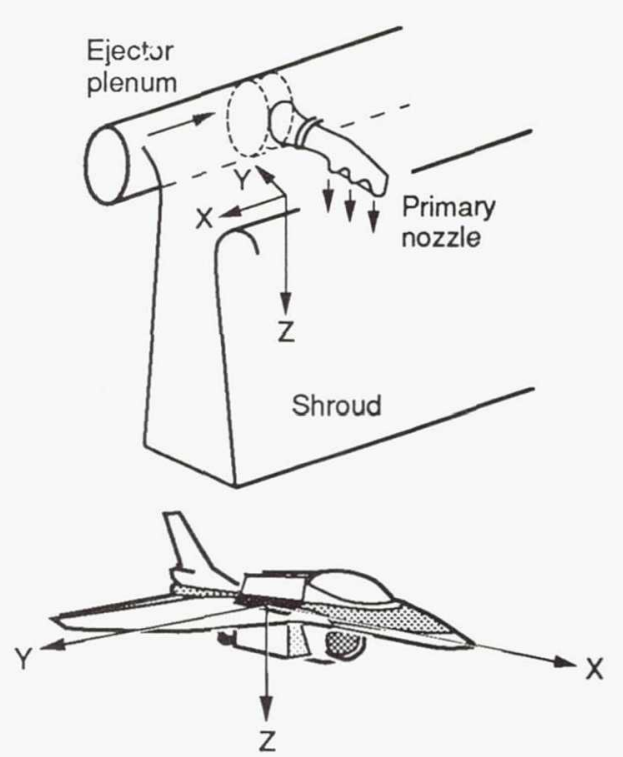

2. Bernal, L. and Sarohia, V., "An Experimental Investigation of Two-Dimensional Thrust Augmenting Ejectors: Final Report, Part II," NASA CR-174110, 1984.

3. Bevilaqua, P.M., "Advances in Ejector Thrust Augmentation," ALAA-84-2425, 1984.

4. Bevilaqua, P.M. and De Joode, A.D., "Viscid/Inviscid Interaction Analysis of Thrust Augmenting Ejectors," ONR CR12-249-1, 1978.

5. Corsiglia, V., Farbridge, J., Dudley, M. and Smith, B., "Large-Scale Wind Tunnel Tests of an EjectorLift STOVL Aircraft Model," ALAA-89-2905, 1989.

6. Garland D.B. and Gilbertson, F.L., "A Review of Scale Effects on the Static Performance of Lift Ejectors," ALAA-90-1819, 1990.

Figure 1.-Ejector aircraft configuration. 


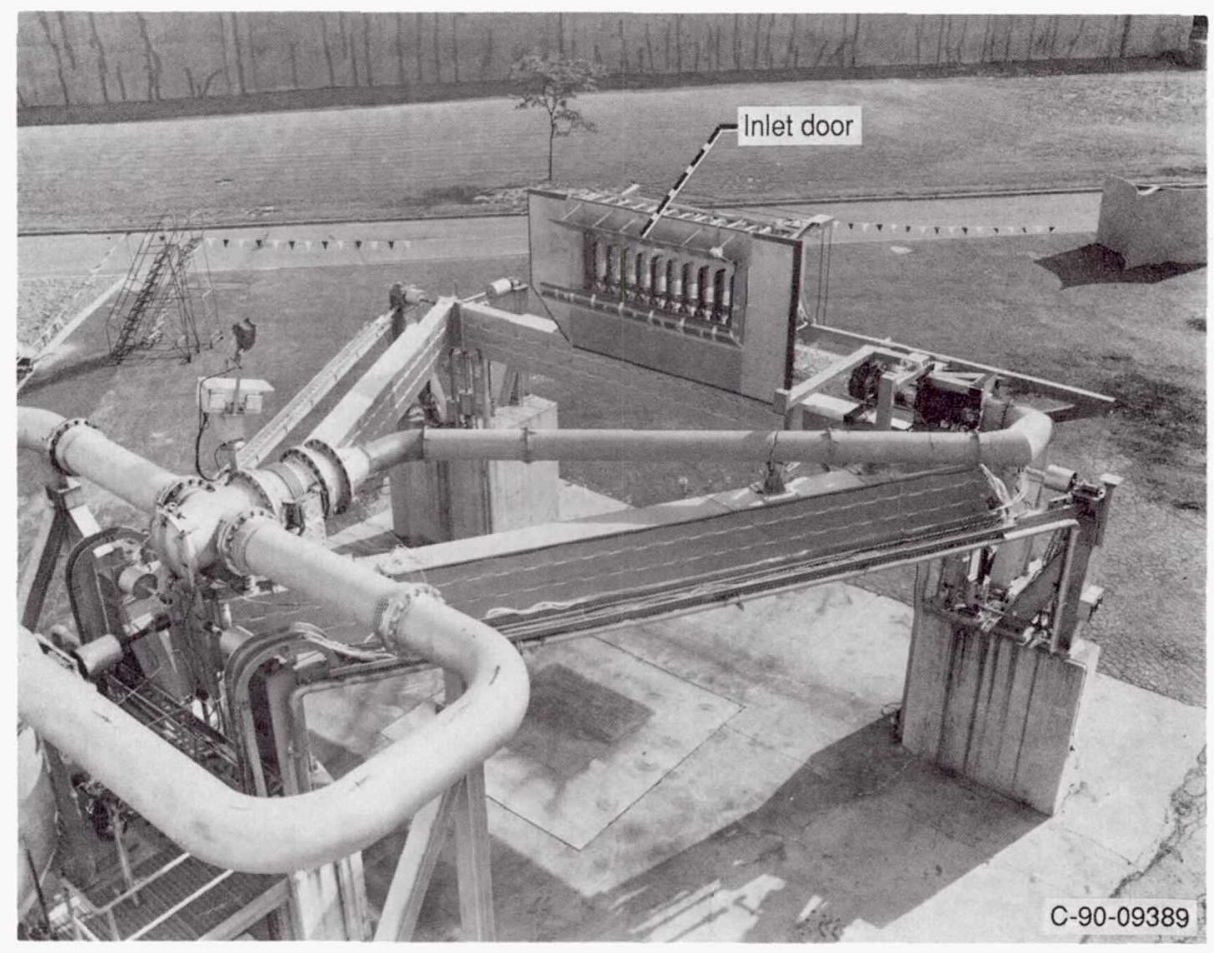

Figure 2.-Ejector installed on the PLF.

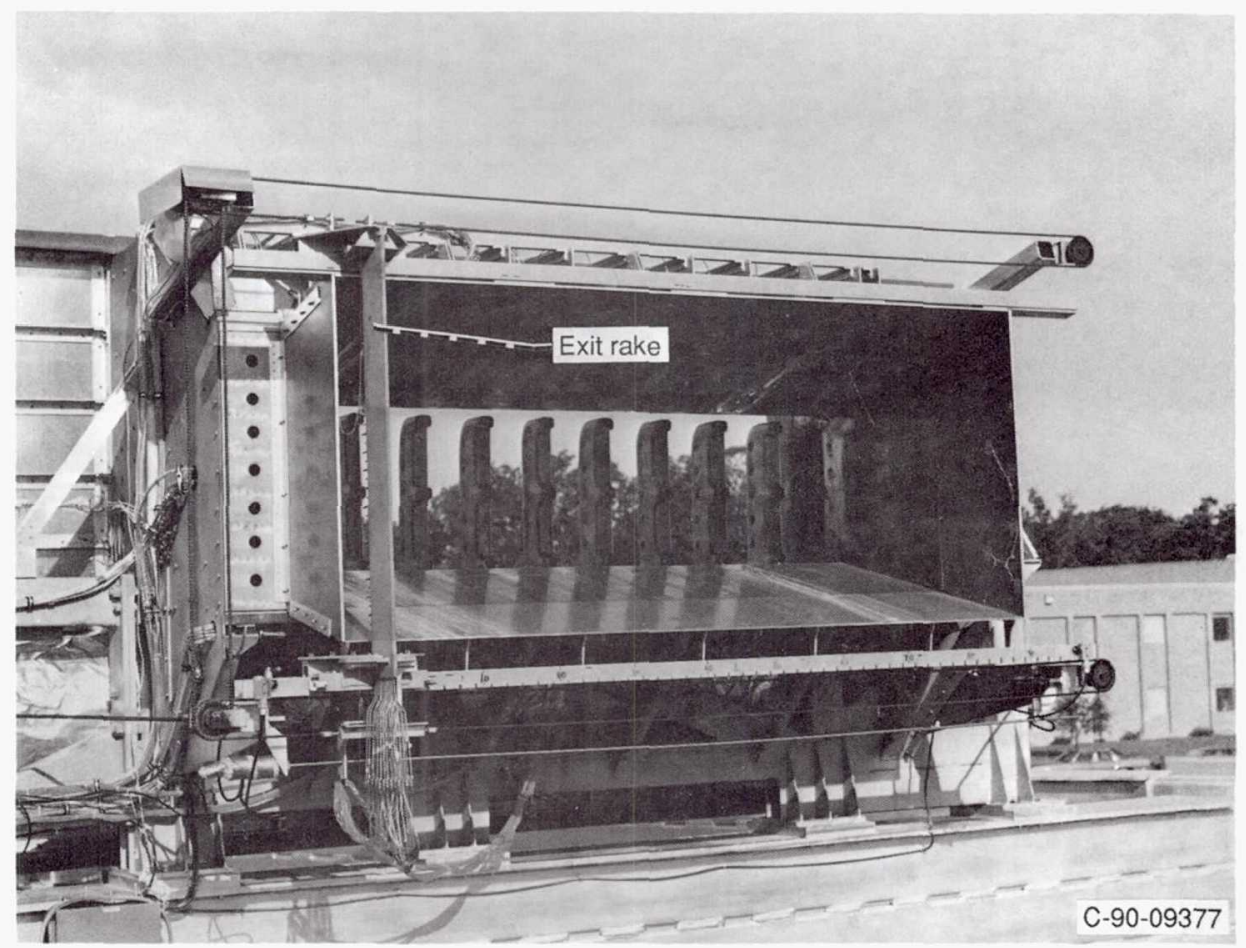

Figure 3.-Ejector exit plane. 


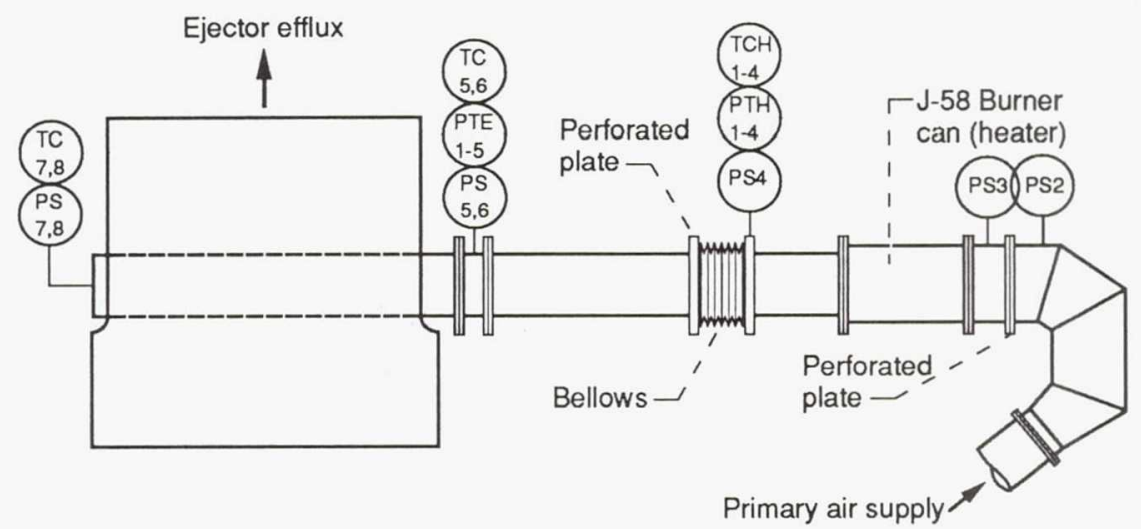

Figure 4.-Primary air supply duct instrumentation.

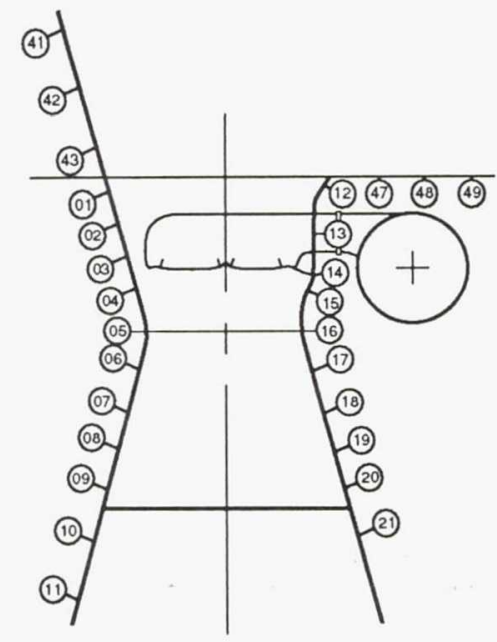

(a) Wall static pressure taps.

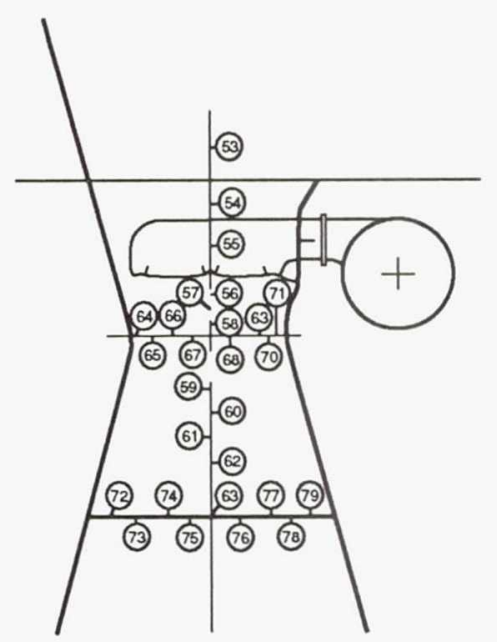

(b) Upstream end-plate static pressure taps.

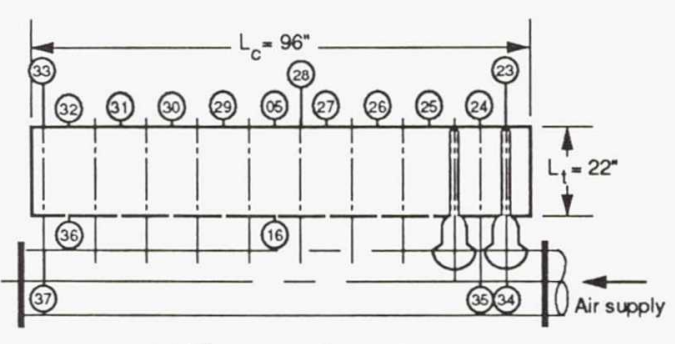

(c) Throat static pressure taps.

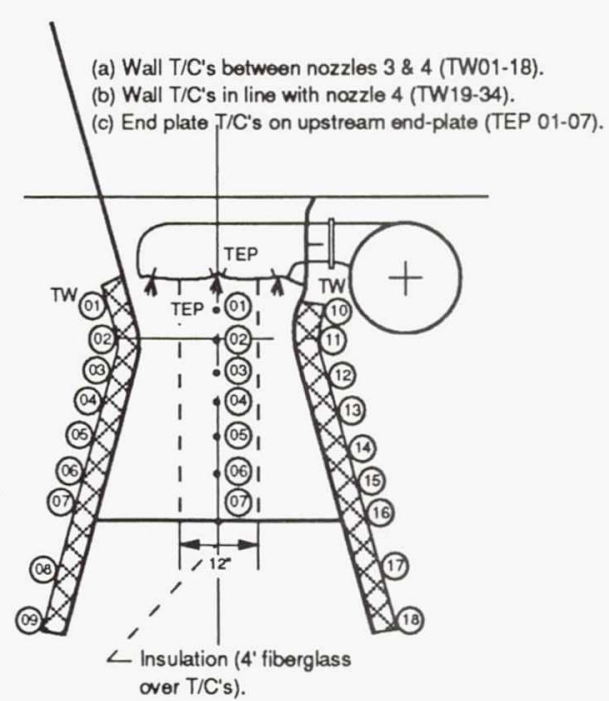

(d) Wall and upstream end-plate thermocouples.

Figure 5.-Ejector instrumentation. 
Configuration

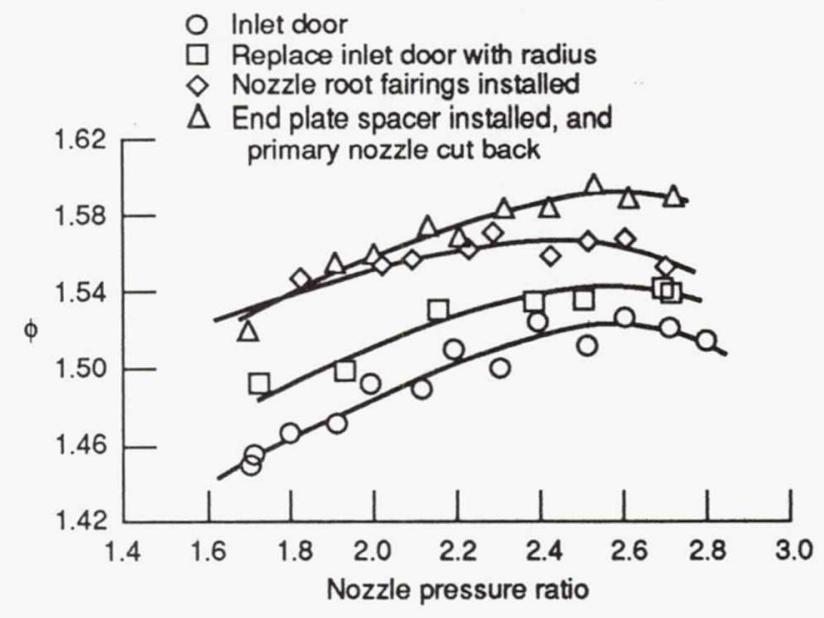

Figure 6.-Cold flow ejector performance.

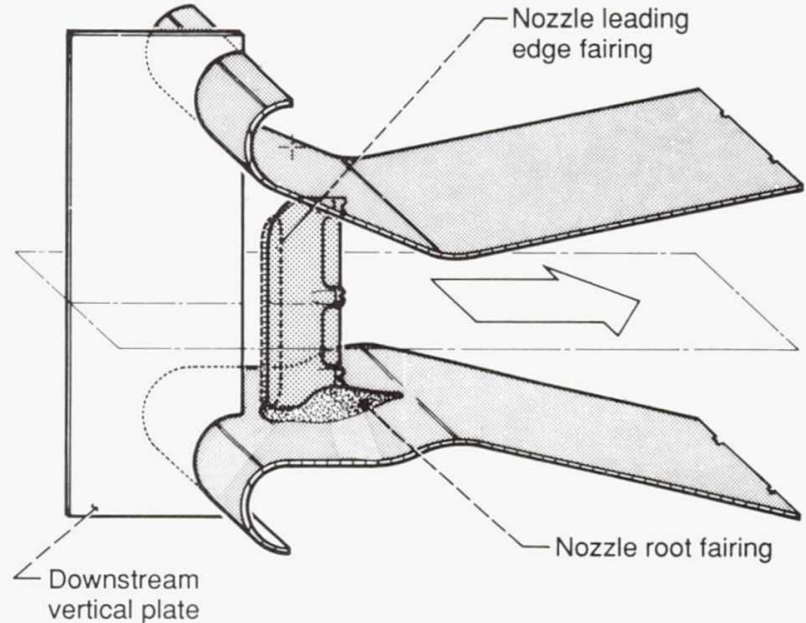

(a) Cross-sectional view of ejector.

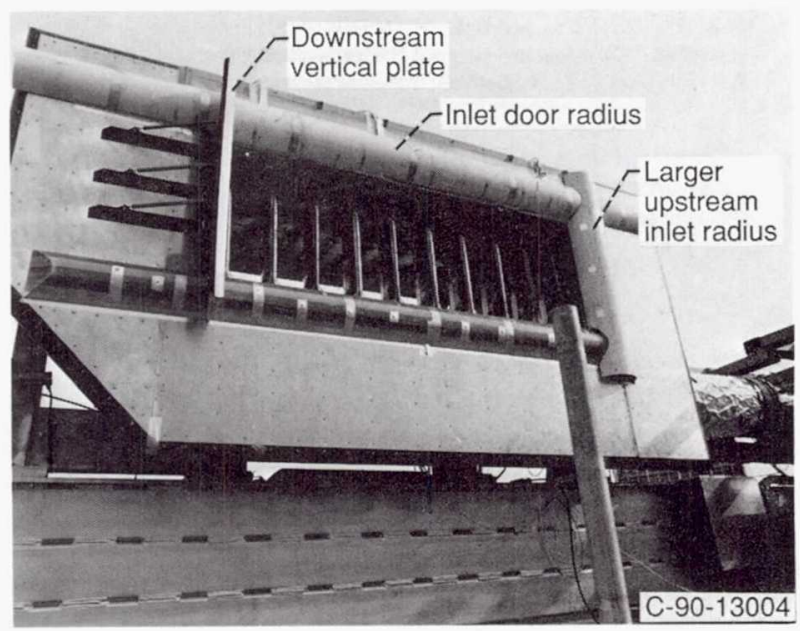

(b) Photo of ejector plan view. Inlet door replaced with radius shown.

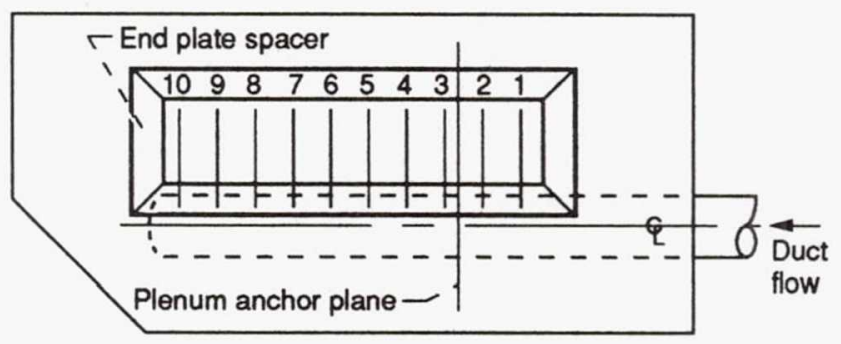

(c) Sketch of ejector plan view.

Figure 7.-Cold flow configuration changes. 


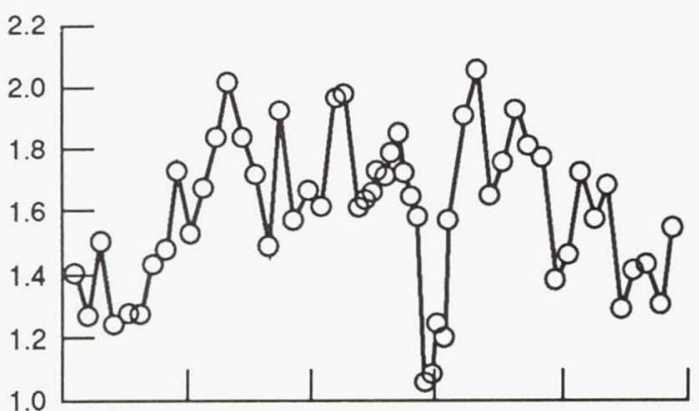

(a) Before primary nozzles cut back.

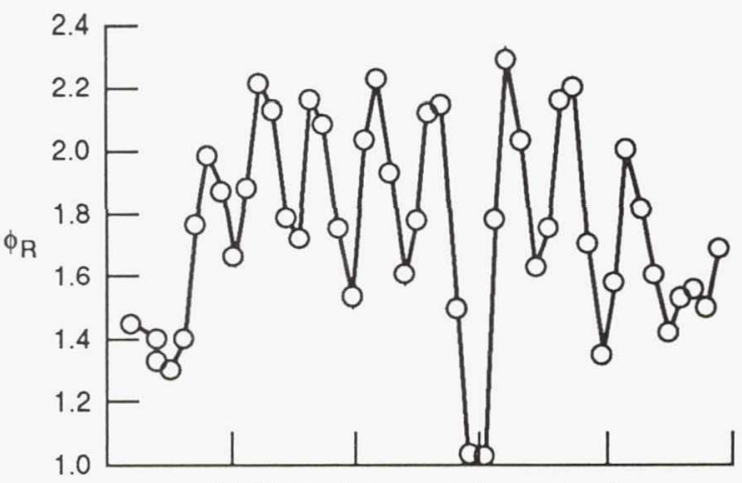

(b) After primary nozzles cut back.

\section{Configuration}

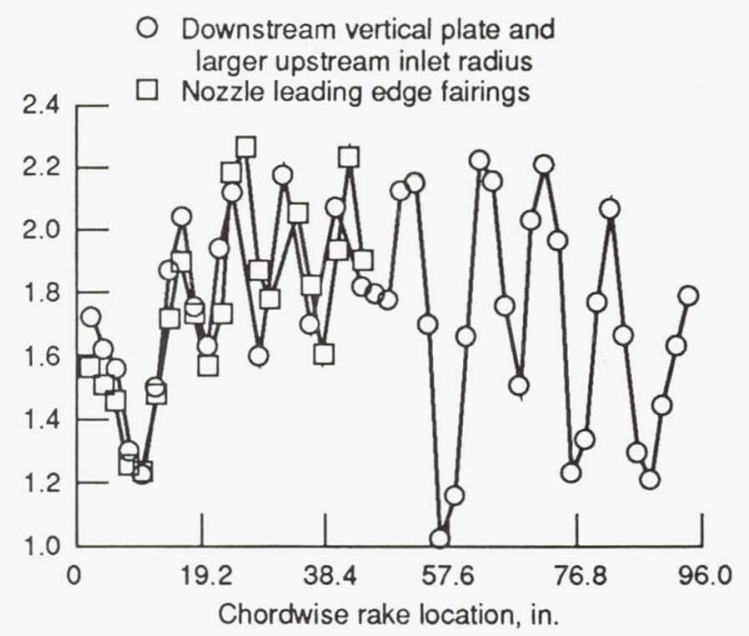

(c) End plate inlet adjustments.

Figure 8. - Cold flow ejector performance at NPR $=2.7$.
O August $\left(T_{\text {ambient }}=535^{\circ} \mathrm{R}\right)$

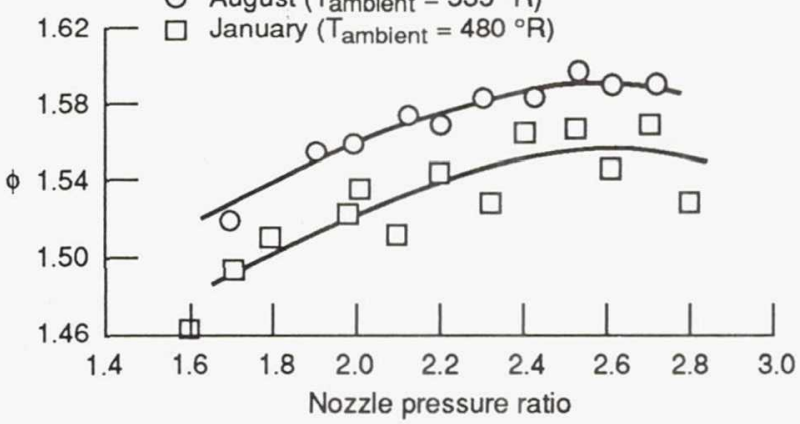

Figure 9.-Effect of seasonal temperature variation on cold flow performance.

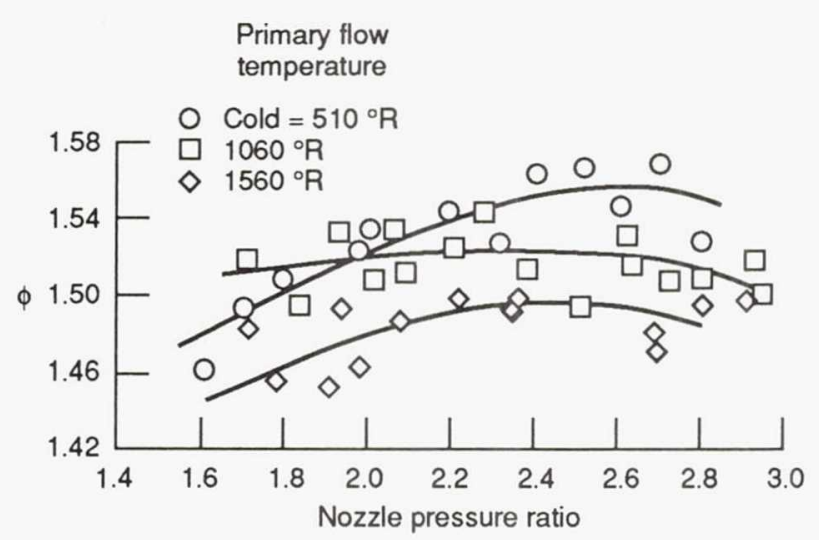

Figure 10.-Hot flow ejector performance. 


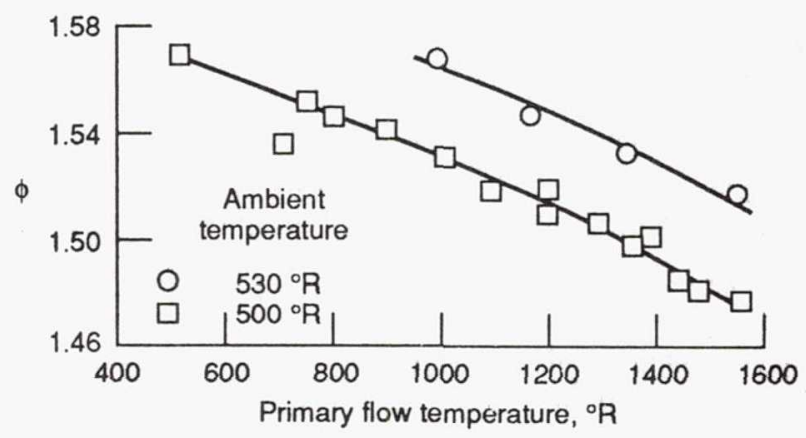

Figure 11. - Ejector performance at NPR $=2.7$.

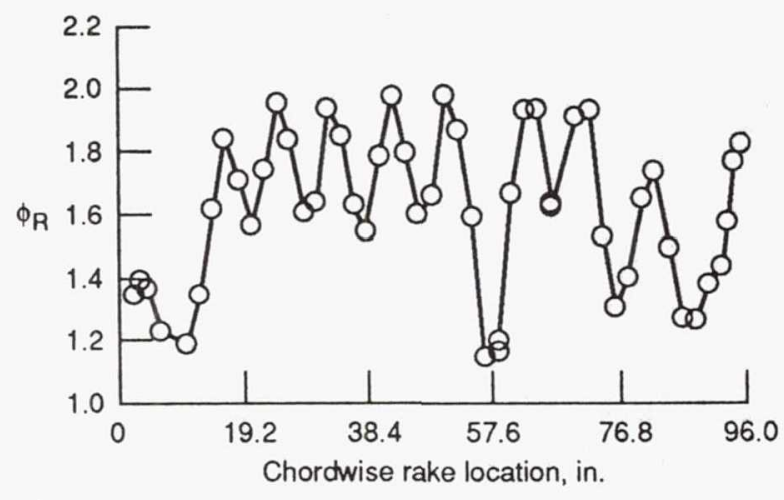

Figure 12.-Design point ejector performance

$\left(T_{\text {Primary }}=1560^{\circ} \mathrm{R}, \mathrm{NPR}=2.7\right)$. 


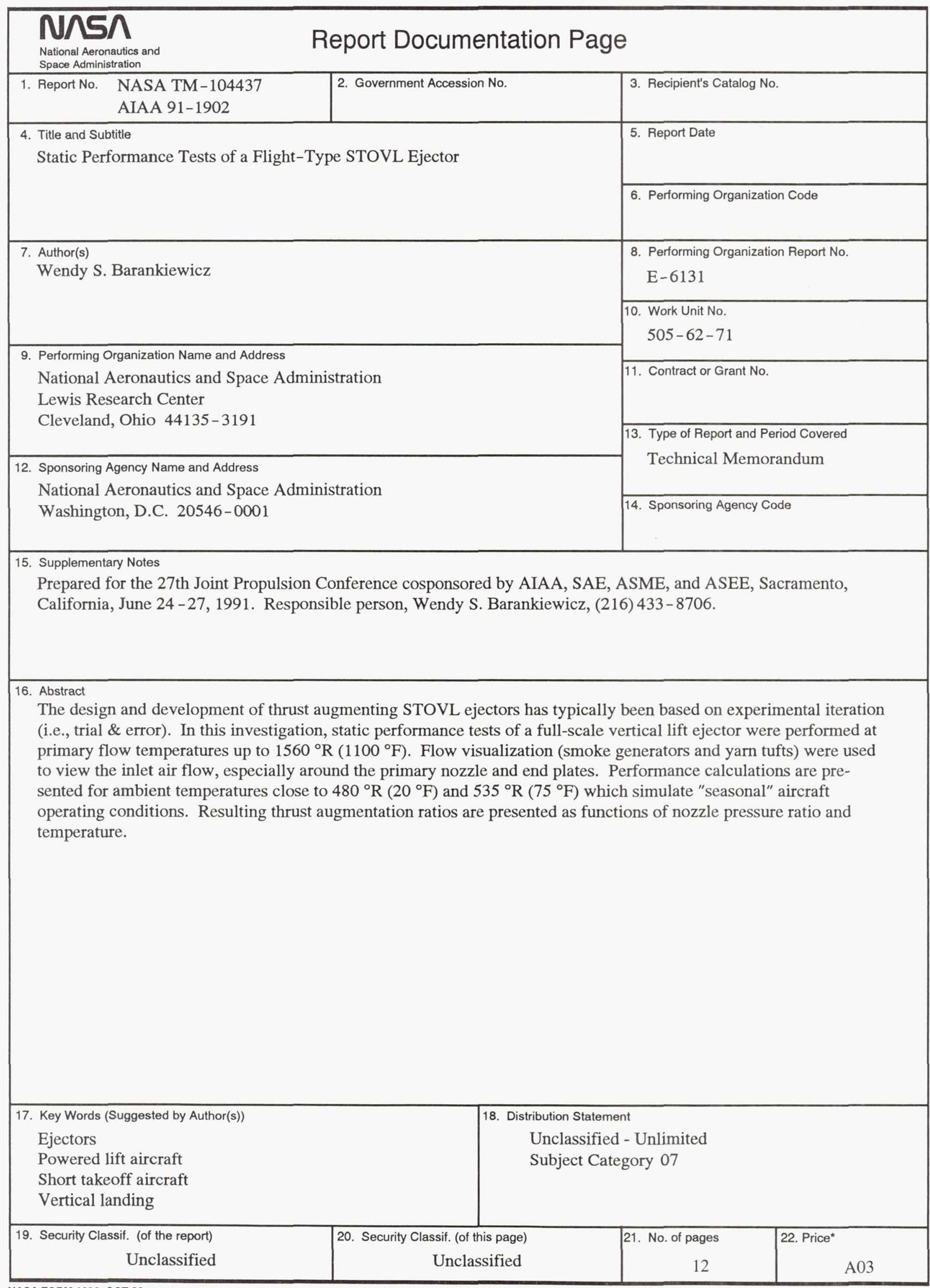

